\title{
Disorder-specific dysfunction in dorsal anterior cingulate cortex and parietal cortex during cognitive reappraisal in anxiety disorder [Letter]
}

This article was published in the following Dove Press journal: Neuropsychiatric Disease and Treatment

\section{Hai-Yang Wang' \\ Bing-Wei Zhang ${ }^{2}$ \\ Xue-Lin $\mathrm{Li}^{3}$}

'Department of Neurology, Jining No. I People's Hospital, Jining, Shandong Province, People's Republic of China; ${ }^{2}$ Department of Neurology and Psychiatry, First Affiliated Hospital of Dalian Medical University, Dalian, Liaoning Province, People's Republic of China; ${ }^{3}$ Department of Intensive Care Unit, Jining No. I People's Hospital, Jining, Shandong Province, People's Republic of China
Correspondence: Xue-Lin Li

Department of Intensive Care Unit, Jining No. I People's Hospital, Jining, No. 6 , Jiankang Road, Jining, Shandong Province 2720II, People's Republic of China Email lixuelin0828@I63.com

\section{Dear editor}

Following our recently published article $^{1}$ in Neuropsychiatric Disease and Treatment, many readers have commented that the effects of comorbid depression cannot be ruled out as a factor in our results, since anxiety disorders and major depression are heterogeneous disorders. We would like to respond to the points made.

Impaired cognitive emotion regulation is commonly seen in many psychiatric disorders. ${ }^{2}$ A recent review concluded that individuals with depressive disorders consistently show decreased activation of the ventrolateral prefrontal cortex (vlPFC) and dorsolateral prefrontal cortex (dlPFC) during cognitive reappraisal. ${ }^{3}$ Moreover, enhanced activity of the amygdala, which is associated with hyperactive bottom-up emotion responses during downregulation of negative emotion, is a disorder-specific deficit in the recruitment of brain regions during cognitive reappraisal in depression disorder. ${ }^{3}$ Our meta-analysis was intended to provide a comprehensive description of the brain mechanisms underlying cognitive reappraisal deficits in anxiety disorder. We concluded that patients with anxiety disorder could not recruit the frontoparietal network, including dorsal anterior cingulate cortex (dACC), parietal cortex, dorsomedial prefrontal cortex and supplementary motor area, to down-regulate their emotion responses.

Notably, we did not find that abnormalities of vlPFC, dlPFC or amygdala activity were involved in anxiety disorder, which suggests that the cognitiveappraisal-related impairments in emotion regulation that occur in anxiety disorders and major depression have different neural correlates. There are several explanations for our negative findings. First, although we included some patients with anxiety disorder accompanied by depression, they were eligible for inclusion in the meta-analysis as anxiety disorder was the primary diagnosis. Second, although some studies reported that patients with anxiety disorder showed diminished vIPFC and dIPFC activity during downregulation of negative emotion, ${ }^{1}$ the results are mixed. Our comprehensive meta-analysis was performed to provide a robust description of the neurobiological underpinnings of anxiety. Third, although patients with major depression consistently show enhanced amygdala activity during cognitive reappraisal, ${ }^{3}$ none of the eight studies included in the meta-analysis reported enhanced amygdala during cognitive reappraisal in anxiety disorders. ${ }^{1}$ 
Using a more stringent significance criterion $(p<0.001)$, we found that during cognitive reappraisal patients with anxiety disorder showed decreased activity relative to healthy controls in the dACC (peak MNI: 4, 12, 42; $p=\sim 0 ; \mathrm{Z}=-2.838$; voxels 2129) and parietal cortex (peak MNI: -48, -28, 46; $p=0.000002563 ; \mathrm{Z}=-2.329$; voxels $=544$ ); thus, the main findings remained largely unchanged. The dACC is involved in allocating control and attentional resources during cognitive reappraisal, ${ }^{4}$ whilst parietal cortex is mainly associated with selective attention and may be involved in holding reappraisals in mind. ${ }^{5}$ Our results indicate that, in anxiety disorder, diminished AACC and parietal cortex activity may impair the allocation of attention and control during cognitive reappraisal. It should be noted that none of the nine major depressive disorder studies we reviewed reported reduced $\mathrm{dACC}$ and parietal cortex during cognitive reappraisal. ${ }^{3}$ Importantly, patients with anxiety disorder, unlike those with major depression, did not show enhanced amygdala activity or reduced vlPFC and dIPFC activity during cognitive reappraisal. Conversely, patient with major depression did not show decreased activation of the $\mathrm{AACC}$ and parietal cortex, unlike those with anxiety disorder. We believe, therefore, that the effects of comorbid depression in anxiety disorder on cognitive reappraisal in our meta-analysis are negligible or non-existent.

These findings offer insight into the neurobiology of emotion dysregulation in anxiety disorder. They provide robust evidence that frontoparietal network impairments play a key role in the pathogenesis of anxiety disorder. More specifically, it appears that dysfunctions of dACC and parietal cortex, which are involved in allocation of attention and control, are relatively specific to anxiety disorder, rather than depression.

\section{Disclosure}

The authors report no conflicts of interest in this communication.

\section{References}

1. Wang HY, Zhang XX, Si CP, et al. Prefrontoparietal dysfunction during emotion regulation in anxiety disorder: a meta-analysis of functional magnetic resonance imaging studies. Neuropsychiatr Dis Treat. 2018;14:1183-1198. doi:10.2147/NDT.S165677

2. Sampath D, Sathyanesan M, Newton SS. Cognitive dysfunction in major depression and Alzheimer's disease is associated with hippocampal-prefrontal cortex dysconnectivity. Neuropsychiatr Dis Treat. 2017;13:1509-1519. doi:10.2147/NDT.S136122

3. Zilverstand A, Parvaz MA, Goldstein RZ. Neuroimaging cognitive reappraisal in clinical populations to define neural targets for enhancing emotion regulation. A systematic review. Neuroimage. 2016;151:105-116. doi:10.1016/j.neuroimage.2016.06.009

4. Amitai S, Botvinick MM, Cohen JD. The expected value of control: an integrative theory of anterior cingulate cortex function. Neuron. 2013;79(2):217-240. doi:10.1016/j.neuron.2013.07.007

5. Ochsner KN, Silvers JA, Buhle JT. Functional imaging studies of emotion regulation: a synthetic review and evolving model of the cognitive control of emotion. Ann N Y Acad Sci. 2012;1251:E1-E24. doi:10.1111/j.1749-6632.2012.06751.x

Dove Medical Press encourages responsible, free and frank academic debate. The content of the Neuropsychiatric Disease and Treatment 'letters to the editor' section does not necessarily represent the views of Dove Medical Press, its officers, agents, employees, related entities or the Neuropsychiatric Disease and Treatment editors. While all reasonable steps have been taken to confirm the content of each letter, Dove Medical Press accepts no liability in respect of the content of any letter, nor is it responsible for the content and accuracy of any letter to the editor.

\section{Publish your work in this journal}

Neuropsychiatric Disease and Treatment is an international, peerreviewed journal of clinical therapeutics and pharmacology focusing on concise rapid reporting of clinical or pre-clinical studies on a range of neuropsychiatric and neurological disorders. This journal is indexed on PubMed Central, the 'PsycINFO' database and CAS, and is the official journal of The International Neuropsychiatric Association (INA). The manuscript management system is completely online and includes a very quick and fair peer-review system, which is all easy to use. Visit http://www.dovepress.com/testimonials.php to read real quotes from published authors. 